\title{
Corrosion resistance of model ultrafine-grained Al-Li alloys produced by severe plastic deformation
}

\author{
Lukasz Dolega · Bogusława Adamczyk-Cieślak • \\ Jarosław Mizera $\cdot$ Krzysztof Jan Kurzydłowski
}

Received: 17 August 2011/Accepted: 14 November 2011/Published online: 23 November 2011

(C) The Author(s) 2011. This article is published with open access at Springerlink.com

\begin{abstract}
The influence of grain boundaries and fine precipitation on the corrosion behavior was investigated in two model aluminum-lithium alloys, namely (in wt\%) $\mathrm{Al}-1.6 \mathrm{Li}$ (lithium in a solid solution) and $\mathrm{Al}-2.3 \mathrm{Li}$ (lithium in the form of $\mathrm{Al}_{3} \mathrm{Li}$ precipitation), subjected to three different severe plastic deformation (SPD) treatments which refined the microstructure of the alloys to the ultrafine grain size. The SPD techniques used in the experiments were equal channel angular pressing (ECAP), hydrostatic extrusion (HE), and extrusion-torsion (ET). The corrosion behavior was examined using a potentiodynamic polarization test, electrochemical impedance spectroscopy, and an immersion test followed by a SEM surface analysis. The electrochemical tests were conducted in a $0.1 \mathrm{M} \mathrm{Na}_{2} \mathrm{SO}_{4}$ solution added with $100 \mathrm{ppm}$ of $\mathrm{Cl}^{-}$. The immersion tests $(48 \mathrm{~h})$ were performed in a $3.5 \% \mathrm{NaCl}$ solution at room temperature. The results indicate that the pitting potential, pit number, and stability of the passive layer formed on the surface of the substrates undergo changes depending on the average grain size and the presence of precipitation or its lack. The corrosion resistance, examined in the solution mentioned above, appears to increase with decreasing average grain size. The ET method gave the microstructure with the lowest corrosion resistance.
\end{abstract}

Ł. Dolega · B. Adamczyk-Cieślak $(\bowtie) \cdot$ J. Mizera •

K. J. Kurzydłowski

Faculty of Materials Science and Engineering, Warsaw

University of Technology, Wołoska 141, 02-507 Warsaw,

Poland

e-mail: badamczyk@inmat.pw.edu.pl

\section{Introduction}

Severe plastic deformation (SPD) is one of the processes which allow producing ultrafine-grained and nanocrystalline materials. At the present, a wide range of SPD methods are available, including equal-channel angular pressing (ECAP) [1-5], accumulative roll-bonding (ARB) [6-8], hydrostatic extrusion (HE) [9-12], extrusion-torsion (ET) [13, 14], among many others [15-17]. The properties of SPD-processed materials differ greatly from those of their conventional coarse-grained counterparts. The mechanical properties [18-20], thermal stability [21-23], and magnetic $[24,25]$ properties of these materials have already been extensively investigated. However, especially when possible industrial applications are considered, the important parameter which should be taken into account is the corrosion resistance. The lack of knowledge of the corrosion mechanisms which operate in SPD-treated materials can limit their future use, whereas the available data are still scarce. A lot of investigations have experimented with materials such as steel [26, 27], copper [28], or nickel [29], but the SPD methods have only recently been used for processing $\mathrm{Al}-\mathrm{Li}$ alloys and, thus far, a few reports on their corrosion resistance in the passive state after SPD have been published. However, there are many articles about corrosion behavior of other aluminum alloys after SPD [30-35].

Aluminum alloys belong to the group of most important and widely used materials. In many applications their high mechanical strength and low density are essential so that they replace other conventional materials. Moreover, aluminum alloys are easy to recycle, have good formability and a relatively good corrosion resistance, the latter being due to their passivation capabilities and to the presence of a dense oxide layer which forms within a wide range of environment $\mathrm{pH}(4.5-8)$. 
In this study, the pitting corrosion resistance of two models, aluminum alloys were examined in the solutions enriched with chloride ions $\left(\mathrm{Cl}^{-}\right)$. The examination methods included electrochemical methods and an immersion test followed by a surface- and quantitative-analysis of the pits.

\section{Experimental}

Materials and deformation methods

In order to reduce the number of the metallurgical and microstructural parameters that affect the results and could make them difficult to interpret, two-model $\mathrm{Al}-\mathrm{Li}$ alloys, $\mathrm{Al}-1.6 \mathrm{wt} \% \mathrm{Li}$, and $\mathrm{Al}-2.3 \mathrm{wt} \% \mathrm{Li}$ were selected for the experiments. These alloys allow us to examine the effect, on the corrosion behavior, of the fine precipitation of the $\delta^{\prime}$ phase $\left(\mathrm{Al}_{3} \mathrm{Li}\right)$ which takes place in the $\mathrm{Al}-2.3 \mathrm{wt} \% \mathrm{Li}$ alloy and compare it with that observed in single-phased $\mathrm{Al}-$ $1.6 \mathrm{wt} \% \mathrm{Li}$. In the HE method, the material in the extrusion container is surrounded by a pressure medium. During the extrusion, the piston compresses the pressure medium until the extrusion is completed. In ECAP, the sample is subjected to four ECAP passes and, after each pass, it is rotated by $90^{\circ}$ around its longitudinal axis ( $B_{\mathrm{c}}$ route) [36]. The ET method, on the other hand, consists of changing the deformation path so that the strain-hardening rate is reduced due to deformation localization. In the case of ET the rotation of the die introduces an additional deformation path. In the present experiments, the $\mathrm{Al}-1.6 \mathrm{wt} \% \mathrm{Li}$ samples in the form of rods with the initial diameter $\varnothing=26 \mathrm{~mm}$ were subjected to plastic deformation up to $\varepsilon=4.2$ using the ECAP method and to $\varepsilon=3.8$ in $\mathrm{HE}$. The $\mathrm{Al}-2.3 \mathrm{wt} \% \mathrm{Li}$ samples were also ECAP deformed to $\varepsilon=4.2$, whereas in HE the rod-shaped samples had diameter $\varnothing=10 \mathrm{~mm}$ and were extruded to $\varnothing=3 \mathrm{~mm}$ which gave $\varepsilon=2.8$. No strain values were determined in the ET experiments since in this case it is very difficult to estimate the cumulated strain.

Sample preparation

All the samples were cut by spark machining, perpendicularly to the extrusion direction (HE and ET) or to the $X$-plane (ECAP) (Fig. 1) so as to form rods with the diameter $\varnothing=3 \mathrm{~mm}$ (surface area-7.1 $\mathrm{mm}^{2}$ ).

The samples for corrosion investigations were embedded in a non-conductive acrylic epoxy and cured in air for $24 \mathrm{~h}$. The electrochemical experiments were carried out using samples ground with a silicon-carbide paper (600- and 1200-grit). Another series of samples were prepared for the immersion test and these, after grinding, were additionally polished using a diamond suspension ( 3 and $1 \mu \mathrm{m})$.

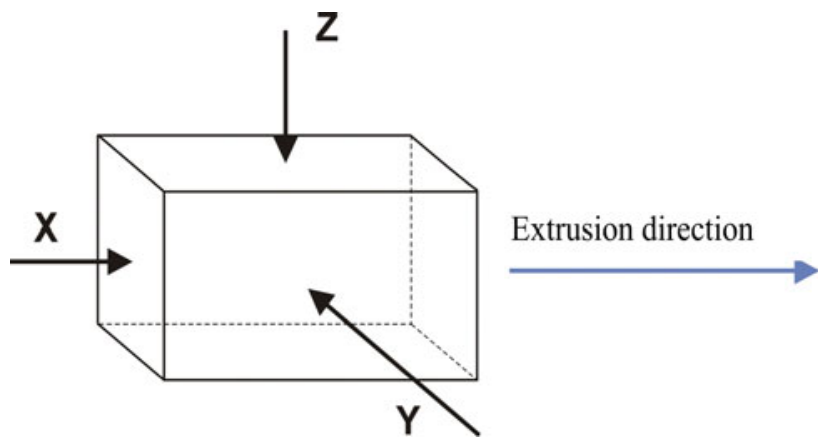

Fig. $1 X, Y, Z$ planes in the sample during ECAP

Corrosive environment

The electrochemical experiments were performed using a $0.1 \mathrm{M}$ sodium sulfate $\left(\mathrm{Na}_{2} \mathrm{SO}_{4}\right)$ solution with $100 \mathrm{ppm}$ of $\mathrm{Cl}^{-}$which enhance pitting corrosion $[37,38]$. An addition of sulfate ions inhibits the incorporation of $\mathrm{Cl}^{-}$into the oxide film due to their competitive adsorption and makes this solution the optimum choice for investigating the passivation and the pitting corrosion resistance of aluminum alloys in the passive state $[39,40]$. In the immersion test, a $3.5 \%$ sodium chloride $(\mathrm{NaCl})$ solution was used so as to simulate sea water. The exposure time was $48 \mathrm{~h}$. All the tests were carried out at room temperature.

\section{Investigation methods}

The alloy microstructures were examined using transmission electron microscopes (TEM) Phillips 300 and JEOL 1200 with accelerating voltages of 100 and $120 \mathrm{kV}$, respectively. The mean grain sizes $\left(d_{\mathrm{eq}}\right.$ defined as the diameter of a circle which has the surface area equal to the surface area of a given grain) were determined by TEM for at least 200 randomly selected grains.

Both the potentiodynamic and the impendence methods were conducted using the AutoLab PGSTAT 100 apparatus with a three-electrode system in which a saturated calomel electrode (SCE) was the reference and a platinum electrode was the counter electrode. In the impendance measurements the frequency ranged from $10^{4}$ to $10^{-2} \mathrm{~Hz}$ and the sinusoidal signal amplitude was $10 \mathrm{mV}$. The impedance spectra obtained were analyzed using an $R\{Q[R(R Q)]\}$ equivalent circuit and a Baukamp's EQUIVCRT software. Prior to the test, all the samples were left in the solution for $600 \mathrm{~s}$ at the open-circuit potential. The potentiodynamic tests were carried out by applying, in the anodic direction, a continuously varying potential of $0.2 \mathrm{mV} / \mathrm{s}$. To insure reproducibility, at least two replicates were run for each sample. If the results were identical (it was in the case of the $\mathrm{Al}-2.3 \mathrm{Li}$ alloy after $\mathrm{HE}$ and ET and $\mathrm{Al}-1.6 \mathrm{Li}$ alloy after HE) two potentiodynamic measurements were carried 
out. In other cases, the corrosion tests were carried out on three or four samples.

The surface analysis of the samples after the immersion test was performed in a scanning electron microscope (SEM) HITACHI 3500. For each sample nine photographs with a magnification of $300 \times$, were taken. The combined surface areas of photographs were $1.035 \mathrm{~mm}^{2}$. The photos were further analyzed by a MicroMeter image analyzing software [41].

\section{Results and discussion}

Extrusion-torsion yields the largest grains, especially in the $\mathrm{Al}-1.6 \mathrm{Li}$ alloy (Fig. 2c). This is because of the recovery processes which proceed very intensively during this process. Dynamic recovery occurs easily during aluminum deformation at room temperature due to the high stack fault energy. The severe strain induced in the material provides enough energy for the dislocations to move from the interior of the grains to the vicinity of the grain boundaries. Moreover, in view of the lack of $\delta$, precipitates in $\mathrm{Al}-1.6 \mathrm{Li}$, the grain growth may be effectively restrained.

In $\mathrm{Al}-2.3 \mathrm{Li}$, ET also produces the largest grains (Fig. 2f), but the difference between this method and the other SPD methods is greatly diminished due to the presence of fine $\delta$ ' precipitates. ECAP allows producing the smallest grains (Table 1), but the microstructure is nonuniform [21]. The SAD pattern shows a diffused ring (Fig. 2e) indicating large misorientation with respect to the non-equilibrium grain which may be due to the dislocations accumulated in great numbers at the grain boundaries. This relatively high dislocation level indicates that residual stress is high. Hydrostatic extrusion gives microstructures similar to those obtained by ECAP, but more uniform (Fig. 2a, d). The accumulated strain in ECAP samples $(\varepsilon=4.2)$ is also higher than that induced by HE $(\varepsilon=3.8$ for $\mathrm{Al}-1.6 \mathrm{Li}$ and $\varepsilon=2.8$ for $\mathrm{Al}-2.3 \mathrm{Li}$ ). In ET, the calculation of strain is, as mentioned before, very difficult.

Fig. 2 TEM photographs of the $\mathrm{Al}-1.6 \mathrm{Li}$ a-c and $\mathrm{Al}-2.3 \mathrm{Li}$ d-f microstructures obtained by three different SPD methods

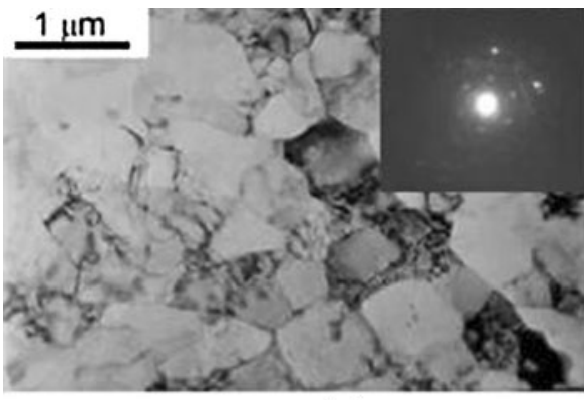

(a) $\mathrm{HE}$

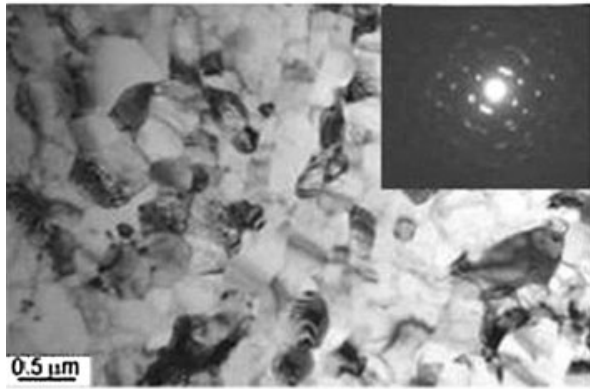

(b) ECAP

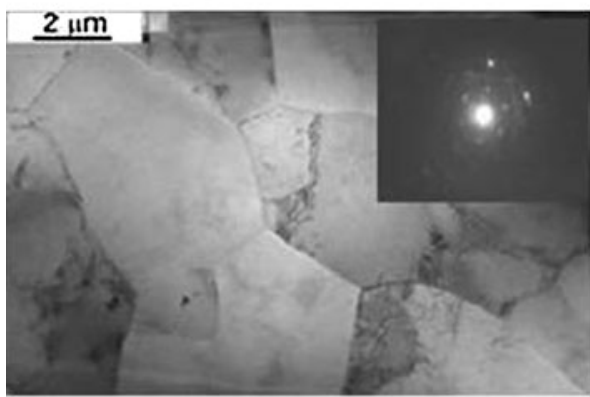

(c) ET

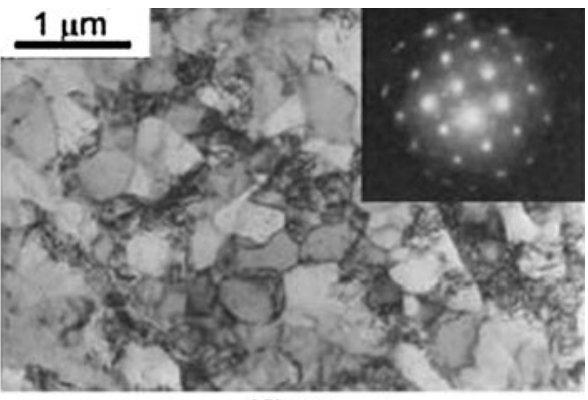

(d) $\mathrm{HE}$

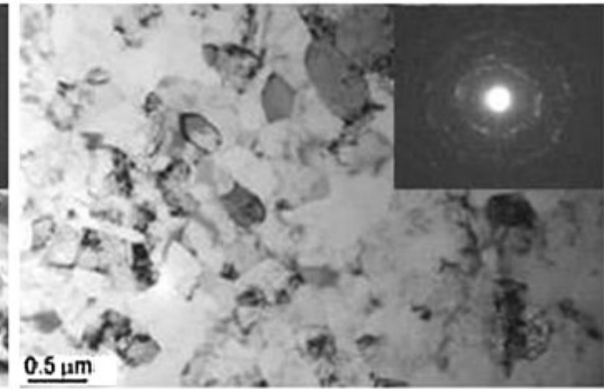

(e) ECAP

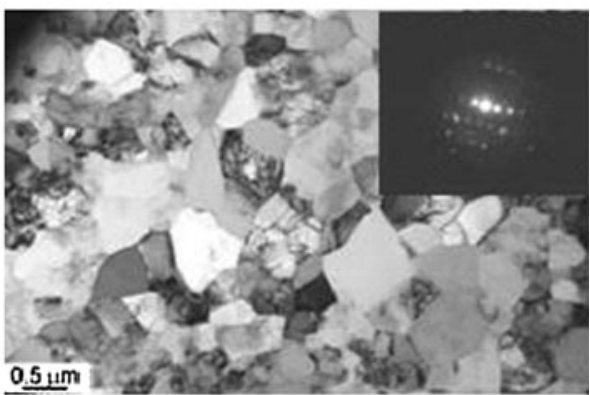

(f) $\mathrm{ET}$ 
Table 1 Average grain size $d_{\mathrm{eq}}$ in the investigated alloys after SPD

\begin{tabular}{llll}
\hline Alloy & Deformation & Section & $d_{\text {eq }}(\mu \mathrm{m})$ \\
\hline Al-1.6Li & ECAP & $X$-plane & 0.33 \\
& HE & Perpendicular & 0.47 \\
& ET & Perpendicular & 1.5 \\
Al-2.3Li & ECAP & $X$-plane & 0.32 \\
& HE & Perpendicular & 0.39 \\
& ET & Perpendicular & 0.47 \\
\hline
\end{tabular}

The potentiodynamic polarization curves obtained for $\mathrm{Al}-1.6 \mathrm{Li}$ and $\mathrm{Al}-2.3 \mathrm{Li}$ in a $0.1 \mathrm{M} \mathrm{Na}_{2} \mathrm{SO}_{4}$ solution with $100 \mathrm{ppm} \mathrm{Cl}^{-}$are shown in Figs. 3 and 4. All the samples are passivated in this solution and undergo pitting corrosion.

The resistance to pitting corrosion can be described in terms of the pitting potential $\left(E_{\mathrm{np}}\right)$ above which the pits grow in a stable way. With the highest values of $E_{\text {np }}$ the corrosion resistance of the specimen is the best. HE-treated $\mathrm{Al}-1.6 \mathrm{Li}$ has a pitting potential of $-50 \mathrm{mV}_{\mathrm{SCE}}$ whereas $\mathrm{Al}-$ 2.3Li deformed by the same method has $70 \mathrm{mV}_{\text {SCE }}$. The pitting potentials of ECAPed samples are $-110 \mathrm{mV}_{\mathrm{SCE}}$ and $-120 \mathrm{mV}_{\mathrm{SCE}}$ for the $\mathrm{Al}-1.6 \mathrm{Li}$ and $\mathrm{Al}-2.3 \mathrm{Li}$, respectively. The lowest resistance to pitting corrosion was found in the specimens subjected to ET in which $E_{\mathrm{np}}$ was equal to $-140 \mathrm{mV}_{\mathrm{SCE}}$ and $-220 \mathrm{mV}_{\mathrm{SCE}}$ in $\mathrm{Al}-1.6 \mathrm{Li}$ and $\mathrm{Al}-2.3 \mathrm{Li}$, respectively.

The samples were also examined by electrochemical impedance spectroscopy (EIS). The spectra in the form of the Bode plots are shown in Fig. 5.

An equivalent circuit with two time constants was used to analyze the results (Fig. 6).

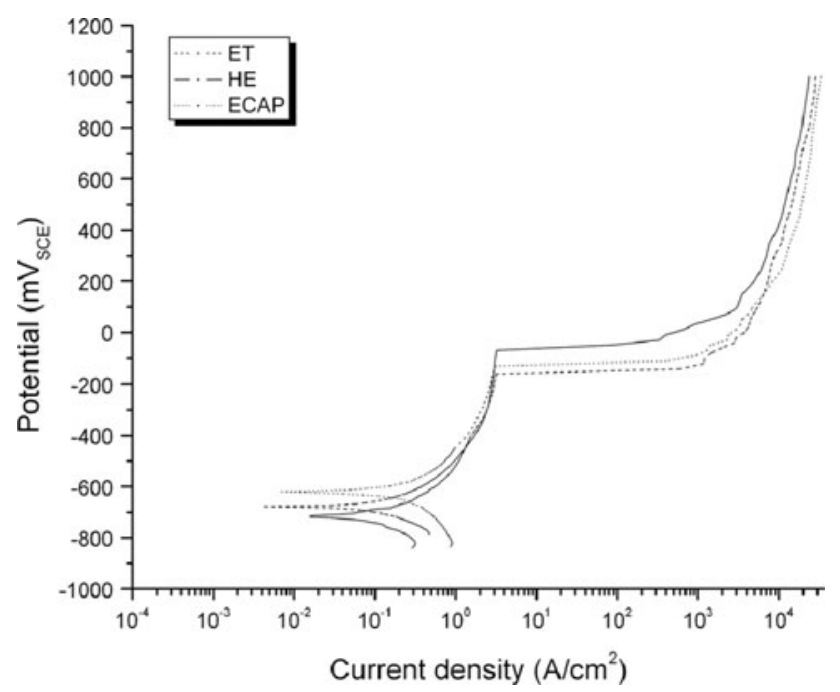

Fig. 3 Potentiodynamic polarization curves obtained for $\mathrm{Al}-1.6 \mathrm{Li}$ in $0.1 \mathrm{M} \mathrm{Na}_{2} \mathrm{SO}_{4}$ solution with $100 \mathrm{ppm} \mathrm{Cl}^{-}$

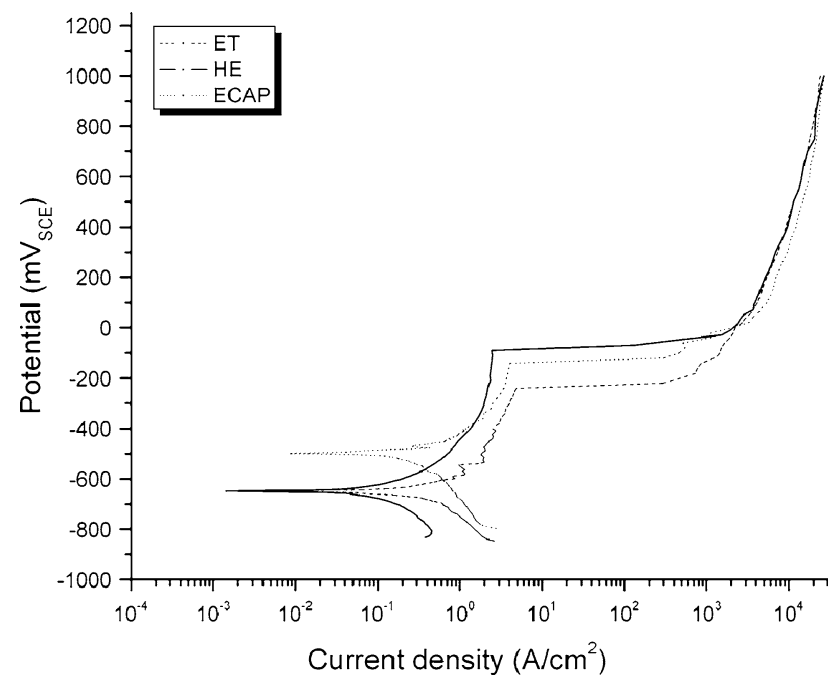

Fig. 4 Potentiodynamic polarization curves obtained for $\mathrm{Al}-2.3 \mathrm{Li}$ in $0.1 \mathrm{M} \mathrm{Na}_{2} \mathrm{SO}_{4}$ solution with $100 \mathrm{ppm} \mathrm{Cl}^{-}$

The resistance to pitting corrosion was determined as the resistance (R1) of the inner oxide layer (the main peak on the Bode spectra) whereas the resistance of the diffusion layer (R2) was neglected. All the spectra have similar shapes which indicate that the electrochemical behavior is the same, but in Fig. 5c additional peaks occur. With both the alloys, HE-treated specimens have the highest resistance whereas in the specimens treated by the two other SPD methods the resistance is evidently lower (Table 2).

The EIS results are in good correlation with those obtained from potentiodynamic polarization except that ECAP-treated Al-2.3Li has a lower resistance than the same alloy after ET. Without however information about the cumulated strain in ET it is difficult to explain why this is so. The better corrosion resistance of $\mathrm{Al}-1.6 \mathrm{Li}$ alloy with smaller grain size is connected with higher density of grain boundaries and dislocations inside grains. This causes the drive system to achieve energy equilibrium state through fast passivation of surface and homogeneous corrosion. The formation of oxide layer on surface is easier in case of sample with ultrafine grain size because of higher energies stored in the non-equilibrium grain boundaries and high internal stress generated during SPD. The high fraction of oxide layer occurs rapidly resulting in lower corrosion rate for alloy with smaller grain sizes. The results of the present study agree well compared with [42], where the ARB refinement of grain size in $\mathrm{Al}-\mathrm{Mn}$ aluminum alloy was analyzed. The large volume of non-equilibrium grain boundaries and high stresses inside the grains results in passive layer. The surface oxide layers of ultrafine-grained sample are more and uniform in comparison with its coarse-grained counterpart.

The results of the surface analysis and quantitative analysis of the pits give evidence that fine precipitation 
Fig. 5 Impedance spectra obtained for $\mathrm{Al}-1.6 \mathrm{Li}(\mathbf{a}-\mathbf{c})$ and $\mathrm{Al}-2.3 \mathrm{Li}(\mathbf{d}-\mathbf{f})$

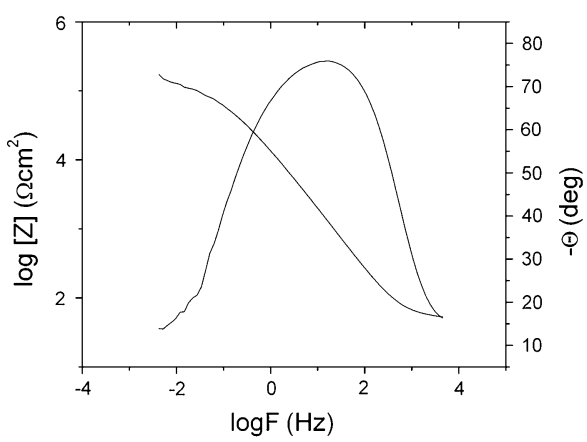

(a) ECAP

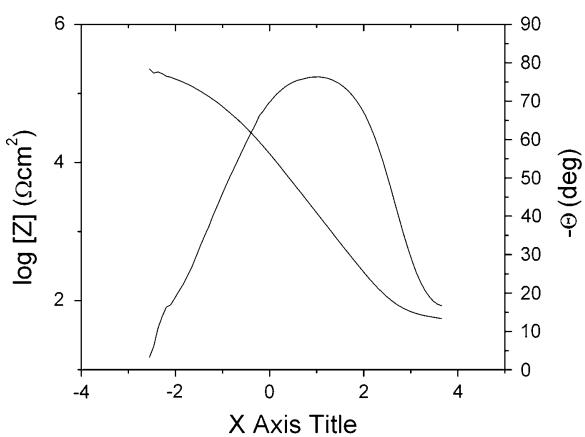

(b) $\mathrm{HE}$

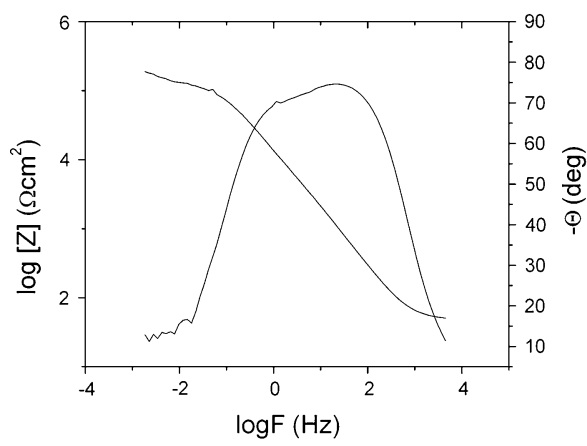

(c) $\mathrm{ET}$

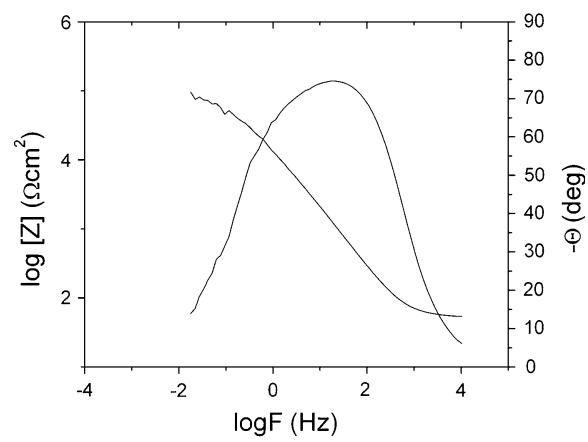

(d) ECAP

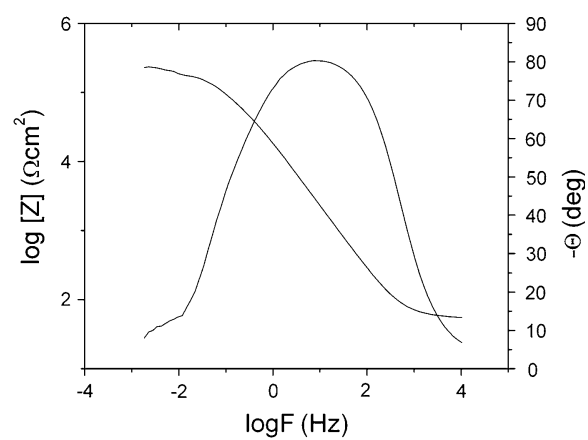

(e) $\mathrm{HE}$

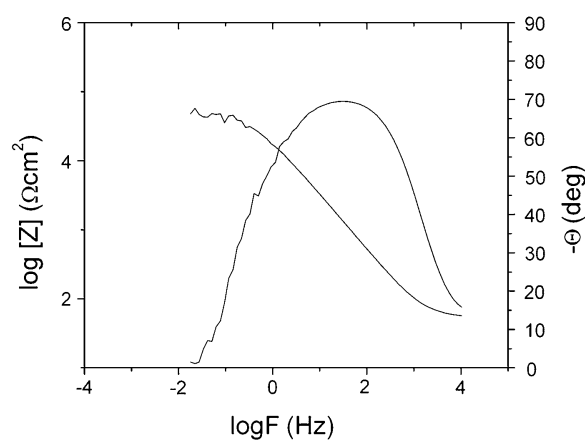

(f) $\mathrm{ET}$

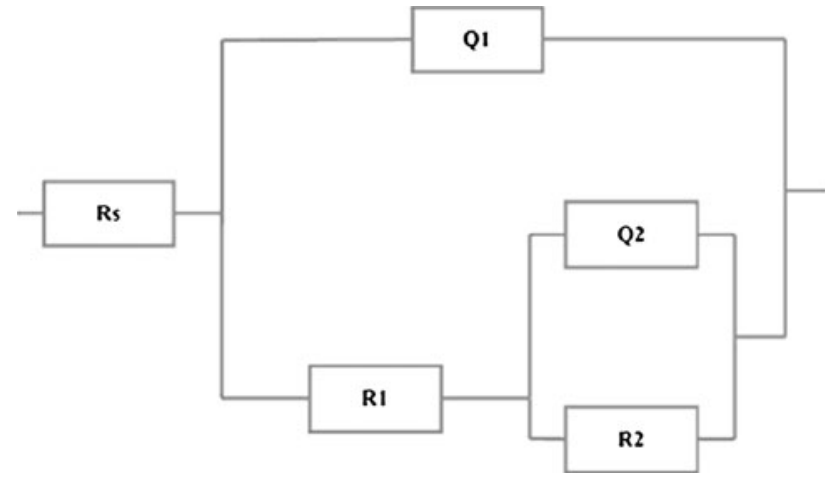

Fig. 6 Equivalent circuit $\mathrm{R}\{\mathrm{Q}[\mathrm{R}(\mathrm{RQ})]\}$. $R s$ resistance of the solution, $R 1$ resistance of the porous layer, $R 2$ charge transfer resistance through the double layer, $Q 1$ capacitance of the intact layer, $Q 2$ capacitance of the double layer affects the corrosion resistance. Examples of the pits can be seen in Fig. 7.

The number of pits is much greater in $\mathrm{Al}-2.3 \mathrm{Li}$ than in $\mathrm{Al}-1.6 \mathrm{Li}$ (Fig. 8). Moreover, in $\mathrm{Al}-1.6 \mathrm{Li}$, where the differences in the average grain size vary from $0.33 \mu \mathrm{m}$ (ECAP) through $0.47 \mu \mathrm{m}$ (HE) to $1.5 \mu \mathrm{m}$ (ET), the number of pits decreases with increasing average grain size. The natural oxide layer on aluminum alloys generally hinders the inherently active behavior of this metal. In case of solution containing $\mathrm{Cl}^{-}$, which are the most common aggressive ions initiating pitting corrosion, proceed rapid increase of the current density at a certain potential. Hence, it can be concluded that the pitting corrosion resistance is increased by decreases of grain size.

With $\mathrm{Al}-2.3 \mathrm{Li}$ it is difficult to draw a conclusion since all the treatments give similar grain sizes. However, the number of pits may be lower in ECAP-treated samples, 
Table 2 Comparative results of the impedance measurement tests

\begin{tabular}{lllllll}
\hline Parameter & \multicolumn{1}{l}{ Material } & & & \\
\cline { 2 - 6 } & Al-1.6Li ECAP & Al-1.6Li HE & Al-1.6Li ET & Al-2.3Li ECAP & Al-2.3Li HE & Al-2.3Li ET \\
\hline Resistance R1 $\left(\Omega / \mathrm{cm}^{2}\right)$ & 62,300 & 93,100 & 17,164 & 21,700 & 123,130 \\
Capacitance Q1 $\left(\mathrm{F} / \mathrm{cm}^{2}\right)$ & $1.83 \mathrm{E}-06$ & $1.97 \mathrm{E}-06$ & $1.86 \mathrm{E}-06$ & $1.86 \mathrm{E}-06$ & $2.43 \mathrm{E}-06$ & $4.14 \mathrm{E}-07$ \\
$\mathrm{n} 1$ & 0.87 & 0.87 & 0.88 & 0.88 & 0.91 & 0.82 \\
\hline
\end{tabular}

Fig. 7 Examples of pits formed after $48 \mathrm{~h}$ exposure in a $3.5 \%$ $\mathrm{NaCl}$ solution

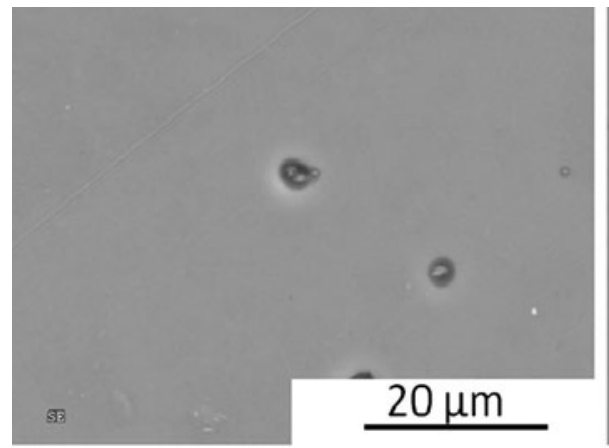

Al-1.6Li_ECAP

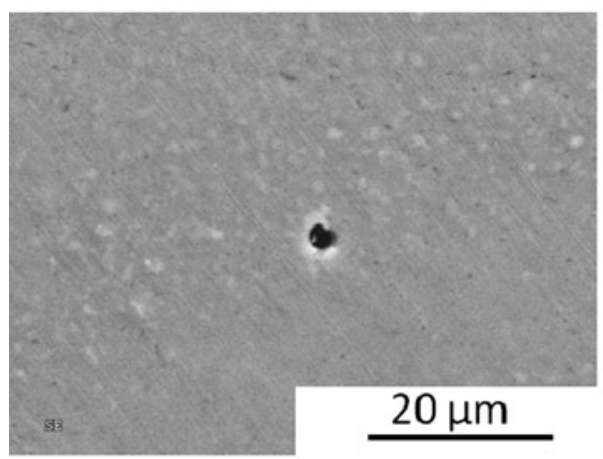

Al-1.6Li_HE

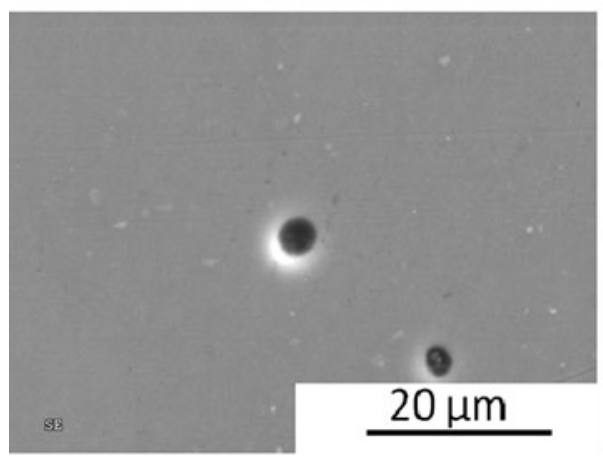

Al-1.6Li_ET

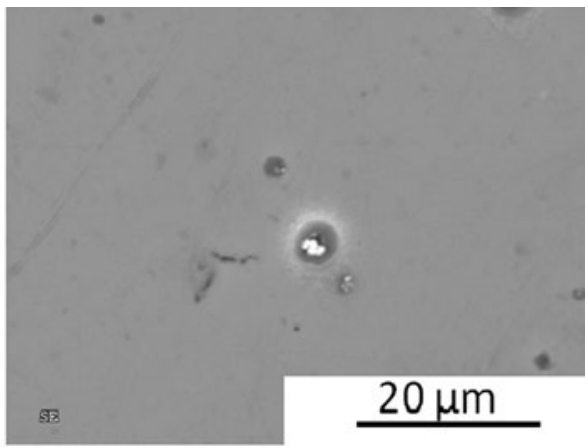

Al-2.3Li_ECAP

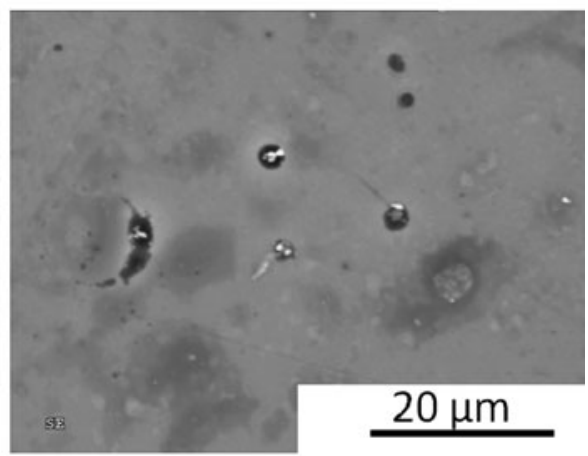

Al-2.3Li_HE

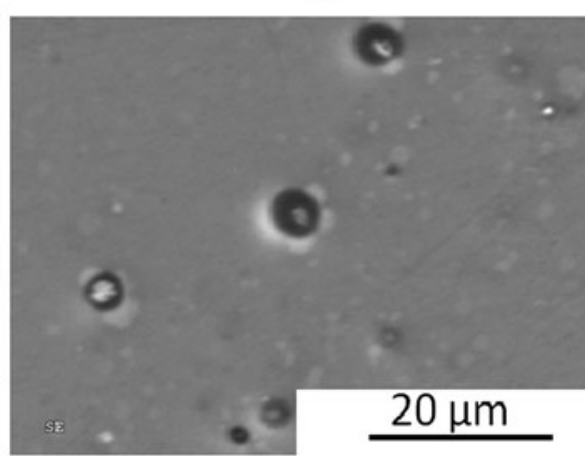

Al-2.3Li_ET whereas the number of larger pits (Fig. 9) seems to be greater in HE and ET-treated samples because of the coalescence and because smaller pits overlap and, in the calculations, were regarded as a single pit with a larger surface area.
It is important to remember that, depending on the properties of the oxide layer, the pits can be repassivated and, thus, the results obtained from the immersion test, even though they could seem to contradict the electrochemical results, only give information on the probability 


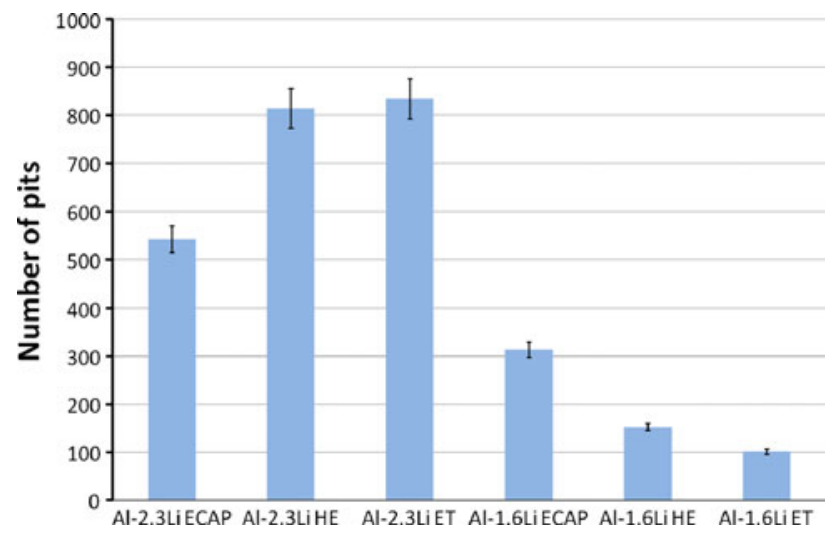

Fig. 8 Pits formed on the sample surface after a $48 \mathrm{~h}$ exposure in $3.5 \% \mathrm{NaCl}$

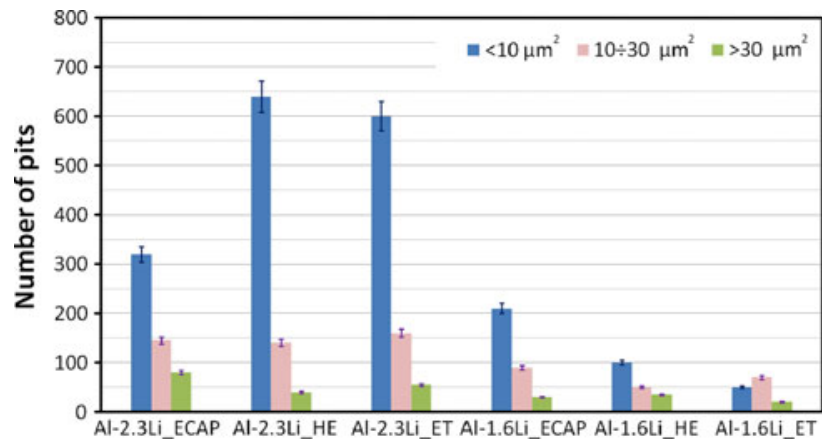

Fig. 9 Distribution of the pit surface area

of pit formation. The resistance of the oxide layer controls the behavior of the pits and their growth.

\section{Conclusions}

Grain size reduction proved to increase dramatically mechanical properties of materials such as hardness and tensile strength, however, its influence on the corrosion behavior of ultrafine-grained and nanocrystalline materials is still not well established. Recently there has been an increasing interest in researching this topic further to provide an understanding of the processes and mechanisms involved in corrosion of materials with greatly reduced grain size. In fact two counteracting phenomenon can be described when material is in active state. One of them is increased reactivity, therefore increased corrosion rate and the second one is higher chemical homogeneity and more uniform distribution of inclusions, which decrease rate of corrosion reactions. One of the things that are certain is a fact that after SPD methods the microstructure has a high density of defects. They are referred to as coordinatively unsaturated sites and are anticipated to have higher adsorption energy because of their lower than normal coordination. Also sites having lower coordination are formed by the grain boundaries. The surface fraction of grain boundaries (and to some extent triple junctions as well) is substantially elevated in ultra fine grained and nanocrystalline materials compared to coarse-grained. Therefore, it is considered to be direct cause of increased electrocatalytic activity in these materials. Huge density of defects and grain boundaries is a key factor increasing diffusion and passivation state. After SPD processing a decrease in size of inclusions and precipitates can be observed [40] accompanied by their dissolution in some aluminum alloys. It results in more uniform distribution of inclusions in the matrix compared to coarse-grained materials. Moreover formation of supersaturated solid solutions and metastable phases can take place increasing corrosion resistance. Nanocrystalline materials can be even single-phased despite the fact, that in when at the equilibrium phase diagram they crystallize into multiphase system [43]. Higher chemical homogeneity leads to decrease of the reactions rate in the corrosion cells at the surface. When that is the case, then partial corrosion reactions happen at lower rate thus limiting and making corrosion more uniform on the surface.

The pitting corrosion resistance of two models aluminum alloys (Al-1.6Li and $\mathrm{Al}-2.3 \mathrm{Li}$ ) subjected to three different deformation processes (HE, ECAP, and ET) was examined. Electrochemical tests have shown that, in both model alloys, HE gives the highest pitting corrosion resistance whereas ET gives the lowest resistance. The results of the potentiodynamic test show that the highest value of the pitting potentials $\left(E_{\mathrm{np}}\right)$ and, thus, the most durable passive layer, was achieved with HE. Moreover, as shown by EIS, the inner oxide layer formed by HE had the highest pitting resistance R1 and was most stable. In $\mathrm{Al}-1.6 \mathrm{Li}$, the least stable oxide layer was that formed by ET, whereas in Al-2.3Li, it was that formed by ECAP. The correlation between corrosion resistance and microstructure after SPD is connected with deformation mode. Similar grain size was obtained after the application of ECAP and $\mathrm{HE}(0.3$ and $0.5 \mu \mathrm{m}$, respectively). Microstructure observation using TEM indicates a similar density of dislocations within the grains. In turn, a different microstructure was observed after ET. Equiaxial, large grains $(1.5 \mu \mathrm{m})$ were formed after deformation. This is probably so, since during deformation by ET the material heats up and grain growth take place. This also resulted in reducing the dislocation density after the deformation as a result of intense dynamic recovery processes. This affects on corrosion resistance-similar in HE and ECAP, and several times lower after ET.

The corrosion resistance of the model Al-2.3 $\mathrm{Li}$ alloy appeared to depend on the presence of fine precipitation of the $\delta^{\prime}$ phase. The model $\mathrm{Al}-1.6 \mathrm{Li}$ alloy (with lithium in a 
solid solution) exhibits better resistance to pitting corrosion (as shown by the electrochemical tests and especially demonstrated in the immersion test).

The number of pits formed in the Al-1.6Li alloy seems to be correlated with the average grain size. It is probable that the grain boundaries, which are here more defected, constitute the preferred initiation sites for pits. In $\mathrm{Al}-2.3 \mathrm{Li}$ the immersion test is less conclusive probably since all the SPD methods give similar grain sizes, but the fact that the number of pits observed in this alloy is substantially greater indicates that their initiation is easier hear than in $\mathrm{Al}-1.6 \mathrm{Li}$.

Acknowledgement Financial support of Structural Funds in the Operational Programme-Innovative Economy (IE OP) financed by the European Regional Development Fund Project 'Modern material technologies in aerospace industry', No. POIG.0101.02-00-015/08 is gratefully acknowledged. The authors are grateful to Dr. Janusz Kamiński for technical assistance.

Open Access This article is distributed under the terms of the Creative Commons Attribution Noncommercial License which permits any noncommercial use, distribution, and reproduction in any medium, provided the original author(s) and source are credited.

\section{References}

1. Valiev RZ, Islamgaliev RK, Alexandrov IV (2000) Prog Mater Sci 45:103

2. Yamasaki T, Miyamoto H, Mimaki T, Vinogradov S, Hashimoto S (2001) Mater Sci Eng A 318:122

3. Kawasaki M, Horita Z, Langdon TG (2009) Mater Sci Eng A 524:143

4. McKenzie PWJ, Lapovok R (2010) Acta Mater 58:3198

5. Lugo N, Llorca N, Cabrera JM, Horita Z (2008) Mater Sci Eng A 477:366

6. Topic I, Höppel HW, Göken M (2008) J Mater Sci 43:7320. doi: 10.1007/s10853-008-2754-3

7. Terada D, Inoue S, Tsuji N (2007) J Mater Sci 42:1673. doi: 10.1007/s10853-006-0909-7

8. Hausöl T, Höppel HW, Göken M (2010) J Mater Sci 45:4733. doi:10.1007/s10853-010-4678-y

9. Lewandowska M, Wejrzanowski T, Kurzydłowski KJ (2008) J Mater Sci 43:7495. doi:10.1007/s10853-008-2810-z

10. Olejnik L, Kulczyk M, Pachla W, Rosochowski A (2009) Int J Mater Form 2:621

11. Kulczyk M, Pachla W, Mazur A, Suś-Ryszkowska M, Krasilnikov N, Kurzydłowski KJ (2007) Mater Sci-Poland 25:991

12. Zherebtsov S, Łojkowski W, Mazur A, Salishchev G (2010) Mater Sci Eng A 527:5596
13. Korbel A, Bochniak W (2004) Scripta Mater 51:755

14. Prusko P, Adamczyk-Cieślak B, Mizera J (2008) Arch Metall Mater 53:199

15. Zrnik J, Pippan R, Scheriau S, Kraus L, Fujda M (2010) J Mater Sci 45:4822. doi:10.1007/s10853-010-4482-8

16. Zhilyaev AP, Ohishi K, Langdon TG, McNelley TR (2005) Mater Sci Eng A 410-411:277

17. Valiev RZ (2007) J Mater Sci 42:1483. doi:10.1007/s10853006-1281-3

18. Terada D, Inoue S, Tsuji N (2007) J Mater Sci 42:1673. doi: 10.1007/s10853-006-0909-7

19. Roven HJ, Nesboe H, Werenskiold JC, Seibert T (2005) Mater Sci Eng A 410-411:426

20. Semenova IP, Valiev RZ, Yakushina B, Salimgareeva GH, Lowe TC (2008) J Mater Sci 43:7354. doi:10.1007/s10853-008-2984-4

21. Adamczyk-Cieślak B, Mizera J, Kurzydłowski KJ (2010) Mater Sci Eng A 527:4716

22. Xu Ch, Furukawa M, Horita Z, Langdon TG (2003) Acta Mater 51:6139

23. Shankar MR, Chandrasekar S, King AH, Compton WD (2005) Acta Mater 53:4781

24. Gleiter H (1989) Prog Mater Sci 33:233

25. Vorhauer A, Rumpf K, Granitzer P, Kleber S, Krenn H, Pippan R (2006) Mater Sci Forum 503-504:299

26. Wang XY, Li DY (2002) Electrochim Acta 47:3939

27. Wang T, Yu J, Dong B (2006) Surf Coat Technol 200:4777

28. Miyamoto H, Harada K, Mimaki T, Vinogradov A, Hashimoto S (2008) Corros Sci 50:1215

29. Rofagha R, Langer R, El-Sherik AM, Erb U, Palumbo G, Aust KT (1992) Mater Res Soc Symp Proc 238:751

30. Akiyama E, Zhang Z, Watanabe Y, Tsuzaki K (2009) J Solid State Electrochem 13:277

31. Roberge PR, Lenard DR (1998) J Appl Electrochem 28:405

32. Hockauf M, Meyer LW, Nickel D, Alisch G, Lampke T, Wielage B, Krüger L (2008) J Mater Sci 43:7409. doi:10.1007/s10853008-2724-9

33. Wei W, Kun Xia W, Qing Bo D (2007) Mater Sci Eng A 454-455:536

34. Son IJ, Nakano H, Oue S, Kobayashi S, Fukushima H, Horita Z (2006) Mater Trans 47:1163

35. Vynar VA (2004) Mater Sci 40:714

36. Valiev RZ, Langdon TG (2006) Prog Mater Sci 51:881

37. McCafferty E (2003) Corros Sci 45:1421

38. Szklarska-Smiałkowska Z (1999) Corros Sci 41:1743

39. Dan S, Ai-bin M, Jing-hua J, Pin-hua L, Dong-hui Y (2009) Trans Nonferrous Metal Soc China 19:1065

40. Chung M-K, Choi Y-S, Kim J-G, Kim Y-M, Lee J-C (2004) Mater Sci Eng A 366:282

41. Wejrzanowski T, Spychalski WL, Rożniatowski K, Kurzydłowski KJ (2008) Int J Appl Math Comput Sci 18:33

42. Wei KX, Wei W, Bo Du Q, Hu J (2009) Mater Sci Eng A 525:55

43. Alves H, Ferreira MGS, Köster U (2003) Corros Sci 45:1833 